\title{
ASSESSMENT OF RAIL VIBRATION TRANSMISSION FROM THE GROUND TO THE FOUNDATION OF A BUILDING
}

\author{
Mariya M oskovets ${ }^{1 *}$ and Nikolay K anev ${ }^{1,2}$ \\ ${ }^{1}$ B M STU, Power Engineering Department, 105005, M oscow, Russia \\ ${ }^{2}$ A ndreyev A coustic Institute, 117036, M oscow, Russia
}

\begin{abstract}
This paper presents the problem of rail transport vibration transmission from the ground to building foundations. Field measurement results of vibration parameters on the ground near buildings and their foundations have been covered in this study. It has been shown that vibrations at the foundation of a building are much smaller than vibrations on the ground. The most intense vibrations on the foundation slab occur in the vertical direction. Comparison with other experimental data on vibration transfer from the ground to buildings structures has been made. The data obtained can be utilized in designing vibration protection measures and to analytically predict vibration effects in buildings. This analysis can be performed after measuring the vibration of rail transport on the ground surface.
\end{abstract}

\section{Introduction}

The most important aspect of environmental impact assessment of infrastructure facilities is evaluating the vibration impact on residents' health and comfort. In large cities rail transport is one of the largest contributors of noise pollution. Unfavourable engineering and geological conditions - as well as economic reasons - forces constructors to lay underground tunnels at a shallow depth, only several meters below the surface. Compaction of buildings makes new buildings to be located close to railways, tram lines and subway tunnels. As a result, the vibration generated by train movements is transmitted to the ground, then transferred to the foundation of the building and spread across its structure. The most acute problem of increased vibratory impact is in residential buildings, where the largest impact can be felt on the lower floors.

While designing a new building, standardized vibration effects are taken into consideration. Documents released by health and wellbeing agencies describe the permissible levels of vibration exposure. The sanitary standards SN 2.2.4/2.1.8.566-96 allows making both spectral and integral estimates in terms of time of exposure [1].

*Corresponding author: ambernebula@icloud.com 
L ogarithmic levels of vibration velocity and vibration acceleration in octave bands are used as spectral characteristics. Integral evaluation involves measuring corrected vibration velocity and vibration acceleration values, which depend on the exposure time. The biggest drawback of using these sanitary standards is that they do not consider vibration impact time for non-constant vibration. Sanitary regulations do not introduce a formal difference between maximum permissible values of the maximum and the equivalent vibration levels. In this regard, they contradict the code of rules SP 120.13330 .2012 for subway design since the difference between the maximum permissible values of the maximum and equivalent levels of vibration velocity is $10 \mathrm{~dB}$ [2]. The M UK 4.3.3221-14, adopted in 2014, addresses the discrete impact of rail vehicles, including trams. However; it does not interpret the $10 \mathrm{~dB}$ amendment adopted in the sanitary standards [3]. V ibrations in the workplace are al so subject to regulations and monitoring. The Sanitary and Epidemiological Rules and Norms of SanPiN 2.2.4.3359-16 [4] adopted in 2016 contains a list of normalized indicators and parameters, among which there are corrected levels of vibration acceleration. At the same time, for production conditions, spectral characteristics of vibration (levels of vibration acceleration in octave or third-octave frequency bands) are not normalized parameters. This regulation considers the negative physical impact time, taking into account the duration of an 8 hour work shift.

It is mandatory to forecast the vibratory impact on buildings closely located to rail lines as a part of the design procedure of these buildings. For the existing lines, the forecast is made based on the results of field vibration measurements carried out at the construction site. Vibration parameters calculation in the designed building has been carried out using known empirical data on frequency-dependent transfer coefficients of vibration from the ground to the building foundation and structure. A reliable forecast requires a large amount of empirical data. It should cover all typical building structures as well as the mutual location of the vibration source and buildings $[5,6,8]$. This work presents results of vibration acceleration levels measured on the ground and on the foundation of a building near the tunnels of a small underground. Two types of foundation structures are considered: solid concrete slab and pile foundation.

\section{Vibration transmission from the ground to the foundation slab}

Vibration transmission study from the ground to the foundation of the building has been carried out on a building under construction, located near tram lines and metro tunnels. Measurements of vibration acceleration created by the passage of subway trains have been carried out in two stages: on the ground surface before the foundation was cast and on the surface of the foundation slab before the construction of other supporting structures in the building. At the first stage, a vibrometer was placed directly on the ground to record the vibration acceleration level in three axes.

It is well known that on massive foundations the highest levels of vibration acceleration are observed in the vertical direction, i.e. perpendicular to the investigated surface. Therefore; further results are given for the vertical vibration component. A spectral analysis has been performed in order to study vibrations transmission from the ground to the foundation of the building. The spectra of vibrations in the three-octave frequency bands in the RMS mode in five seconds were subject to comparison. The results have allowed to identify five metro train passages with an interval of 15 minutes. For each passes the maximum values of vibration acceleration levels were selected. Fig. 1 shows measured levels of vibration acceleration in the third quarter of frequency bands for each train passage, as well as the average values for all measurements. The maximum vibration acceleration occurs at $40 \mathrm{~Hz}$ and its equal to 72 $\mathrm{dB}$. 


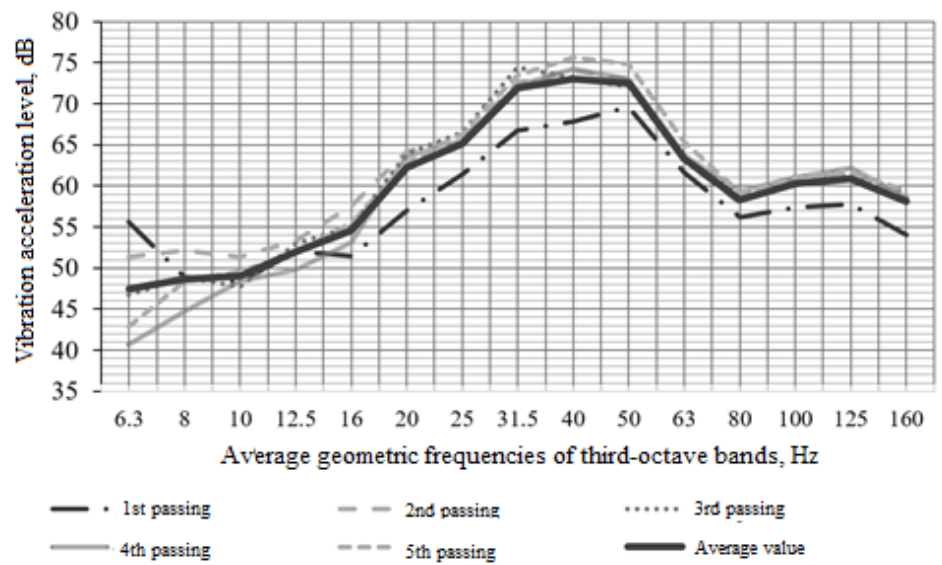

Fig. 1. Vibration acceleration levels on the ground

The second stage of measurements was conducted 8 months after the first one. During this stage, a $1.2 \mathrm{~m}$ thick monolithic concrete slab has been made as a foundation of the building. The vibrometer was placed at the same location as in the first stage. Five passages have been similarly identified. Spectrum averaging has showed that vibration acceleration values are $58 \mathrm{~dB}$ at $50 \mathrm{~Hz}$ (Fig. 2).

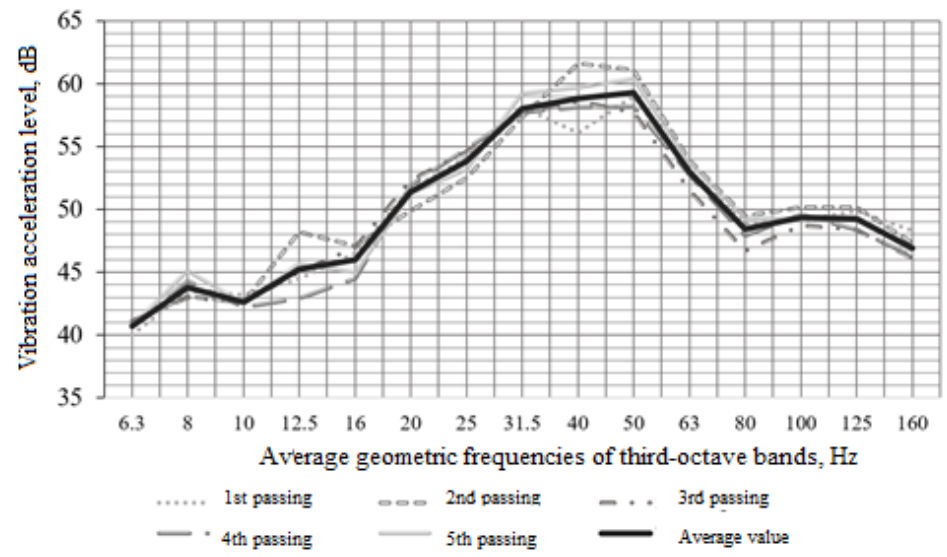

Fig. 2. Vibration acceleration levels on the foundation slab

To characterize vibrations transmission from the ground to the foundation, a transmission factor has been introduced. This factor represents the difference between vibration acceleration levels at two points:

$$
K=L_{1}-L_{2}
$$

Where $L_{1}$ is the average value of vibration acceleration level on the ground in the thirdoctave frequency bands. $L_{2}$ is the average value of vibration acceleration level on the foundation plate.

Frequency dependency of the transmission factor is shown in the Fig. 3. Vibration acceleration level value weakens by some value depending on the frequency. For the 
monolithic concrete slab, the transmission factor is $13 \mathrm{~dB}$ at $31.5 \mathrm{~Hz}$, and in the range from 10 to $14 \mathrm{~dB}$ at the other frequencies.

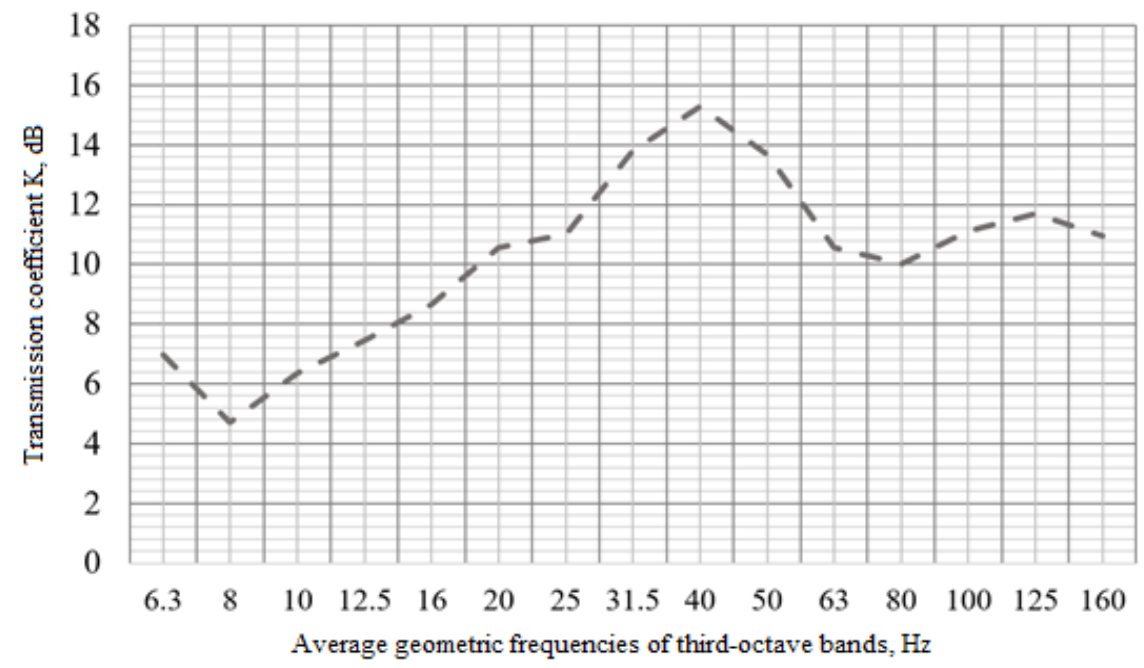

Fig. 3. Frequency dependence of the transmission coefficient vibration from the ground to a $1.2 \mathrm{~m}$ thick solid foundation slab.

\section{VIBRATION TRANSMISSION ON PILE FOUNDATIONS}

A study of the vibrations transmission from the ground to the pile foundation of a building has been also carried out on a building under construction and located near the tunnels of the underground. The pile foundation is a concrete structure which consists of four piles with many smaller capping areas. The piles are buried under the ground (Fig. 4).

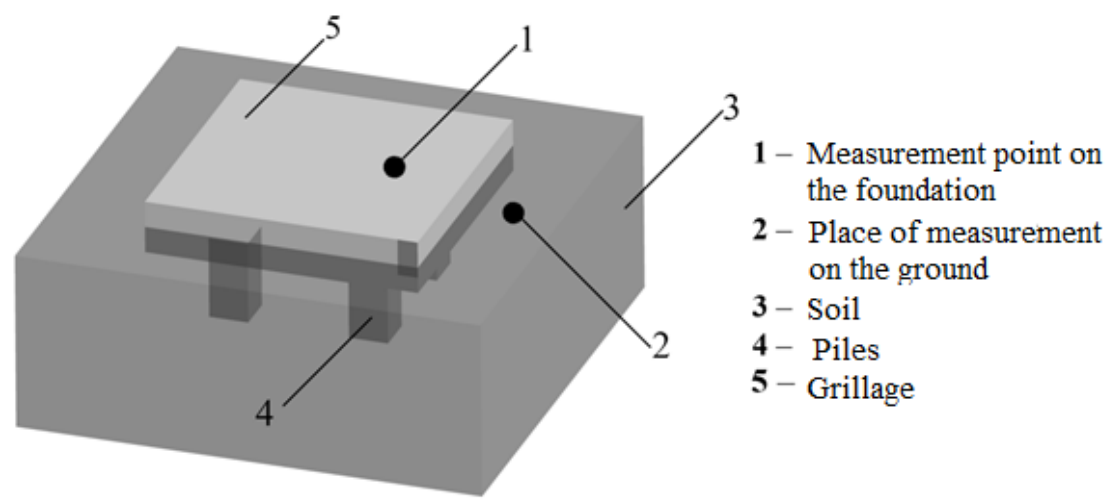

Fig. 4. Schematic diagram of a pile foundation 


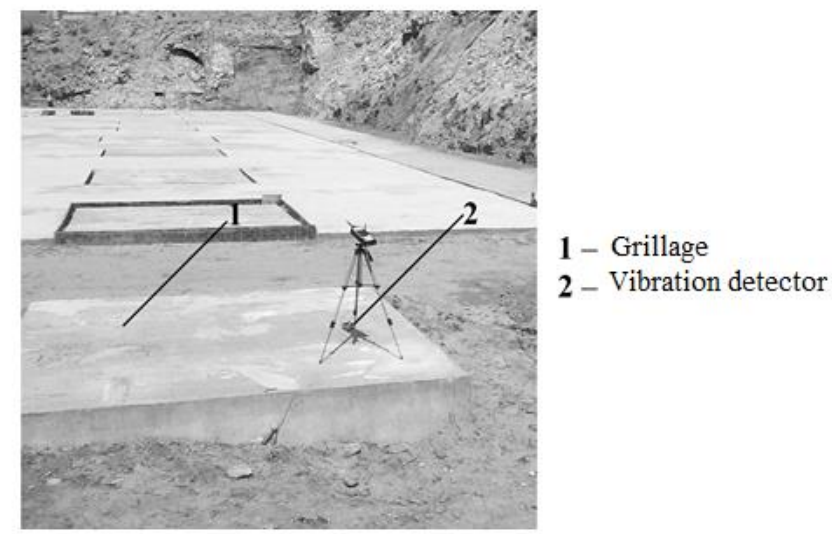

Fig. 5. Vibration acceleration measurements on pile foundations

Conditions of the conducted research are different from the measurements done on the foundation plate in that the measurements have been performed simultaneously at two points. One sensor has been mounted on a grillage, as shown in(Fig. 5), while the other sensor has been placed on the ground. This scenario made it was possible to record vibration acceleration levels from the same train passages. Therefore; reliability of the results in this part is somewhat higher than reliability in the first part of the work.

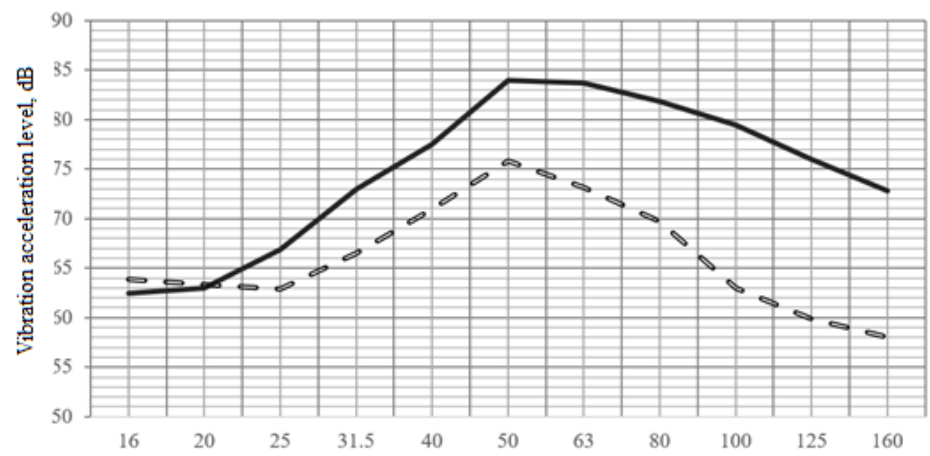

Average geometric frequencies of third-octave frequency bands, $\mathrm{Hz}$

$\longrightarrow$ Ground o o Grillage

Fig. 6. Vibration acceleration levels on the ground and on the grinding surface

Underground part of the building is located about $15 \mathrm{~m}$ away from the underground tunnels. A comparative analysis of the obtained averaged spectra show that the transmission coefficient increases when frequency increases (Fig. 6). At $50 \mathrm{~Hz}$, which corresponds to the maximum measured vibration spectrum (Fig. 7), vibration transmission attenuation is $8 \mathrm{~dB}$. The obtained results at $16-20 \mathrm{~Hz}$ cannot be considered reliable because the measured vibration acceleration levels at these frequencies are close to the background values. 


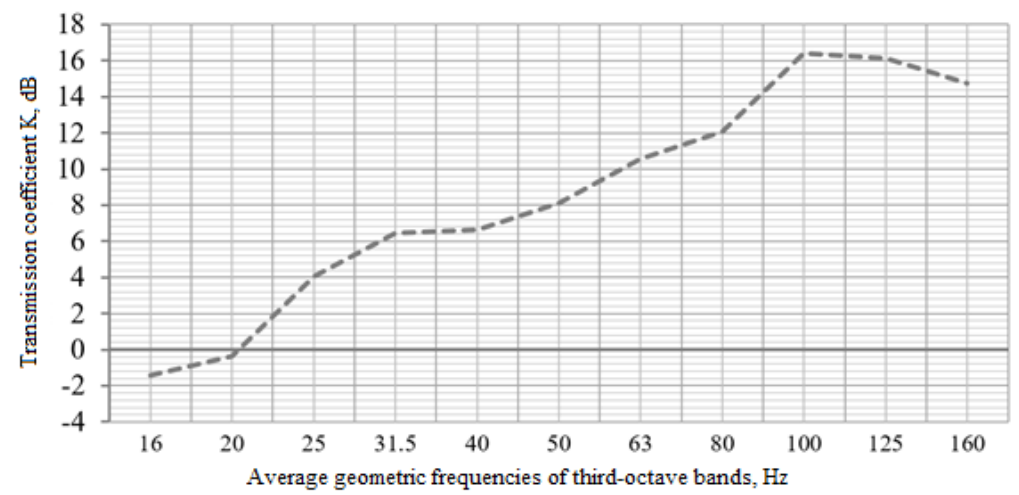

Fig. 7. Frequency dependence of the transmission factor vibration from the ground to the pile foundation

\section{Comparison with FTA recommendations}

The U.S. Federal Transportation Administration issued recommendations on the assessment of transport noise and vibration impact in 2006. These recommendations guide the vibration transmission factor for different types of foundations [7]. Construction features for monolithic foundations and piles have been taken into account.

Based on this recommendation document, it is possible to compare the measured transmission factors of vibration from the ground to the monolithic foundation and to the soil.

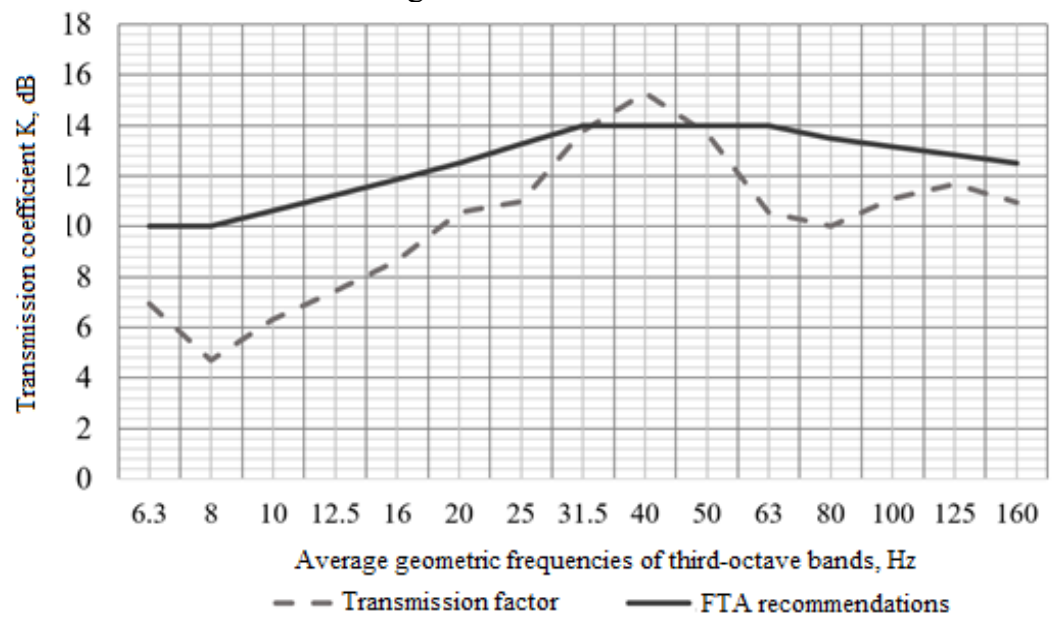

Fig. 8. Comparison of measured and recommended transfer coefficient from soil to the monolithic foundation [7] 


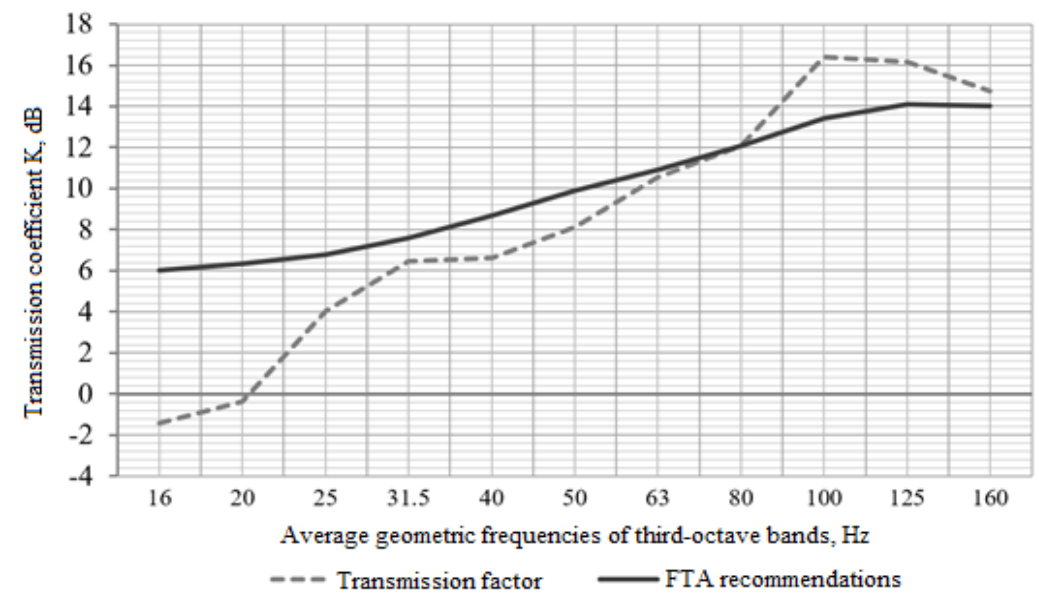

Fig. 9. Comparison of the measured and recommended transfer coefficient from soil to the pile foundation [7]

The comparative analysis has showed a certain convergence between FTA recommendations and the experimental results obtained in this work. Welded foundation transmits a greater vibration from the ground to the building structure than a monolithic foundation.

It should be noticed that results of comparison between the recommended and the empirically obtained values of the transfer coefficient show that reduction in vibration during transfer to the foundation cannot be always sufficient to obtain a favourable vibration picture.

\section{Conclusion}

Vibration acceleration estimates presented in this work show that the vibration transfer from the ground to the foundation is quite significant, although the foundation weakens the vibratory impact transmitted to the building. A welded foundation is better than a foundation slab in reducing vibration attenuation. At the main frequencies of metro vibration spectrum $(31.5-50 \mathrm{~Hz})$, the results obtained well agree with the recommendations [7], which are used in practice to predict the vibration impact on the projected buildings. However; at the other frequencies, a significant discrepancy with recommendations has been found [7].

The data obtained can be used to design vibration isolation measures for buildings exposed to negative impact. Moreover; it can be used to predict vibration impact of rail vehicles near the designed buildings to be constructed. 


\section{REFERENCES}

1. Sanitary rules SN 2.2.4/2.1.8.566-96 Industrial vibration. V ibration in premises of residential and public buildings.

2. SP 120.13330.2012, Subway systems.

3. MUK 4.3.3221-14, Instrumental control and assessment of vibration in residential and public buildings.

4. SanPiN 2.2.4.3359-16, Sanitary and epidemiological requirements for physical factors in the workplace.

5. N. G. Kanev, V ital actvity safety, 11, 16-20 (2018)

6. N. G. Kanev, Protection of buildings against vibrations of surface rail vehicles, in proceedings of VII Russian Scientific and Practical Conference "Protection against High N oise and V ibration", 19-21 M arch 2019, Saint Petersburg, Russia (2018)

7. C. E. Hanson, D. A. Towers, L. D. Meister Transit Noise and Vibration Impact Assessment FTA-VA-90-1003-06, U.S. Department of Transportation Federal Transit A dministration, p. 261 (2006)

8. K. V ogiatzis, H. M ouzakis, Transport, 33(2), 446-453 (2018) 